\title{
Rapid and Inexpensive Preparation of Genome-Wide Nucleosome Footprints from Model and Non-Model Organisms
}

\author{
Laura E McKnight ${ }^{\mathrm{a}}$. Johnathan G Crandall ${ }^{\mathrm{a}}$, Thomas B Bailey ${ }^{\mathrm{a}}$, Orion GB Banks ${ }^{\mathrm{a}}$, Kona N Orlandia ${ }^{\mathrm{a}}$, Vi N \\ Truonga ${ }^{\text {a }}$ Grace L Waddell ${ }^{\mathrm{a}}$, Elizabeth T Wiles ${ }^{\mathrm{a}}$, Drake A Donovan ${ }^{\mathrm{a}}$, Scott D Hansen ${ }^{\mathrm{a}}$, Eric U Selker ${ }^{\mathrm{a}}$, \\ Jeffrey N McKnighta ${ }^{\mathrm{a}, \mathrm{b}, 1}$
}

\author{
a Institute of Molecular Biology, University of Oregon, Eugene OR 97403, USA \\ ${ }^{\mathrm{b}}$ Phil and Penny Knight Campus for Accelerating Scientific Impact, University of Oregon, Eugene OR 97403, USA \\ ${ }^{1}$ Correspondence: jmcknig2@uoregon.edu
}

\begin{abstract}
Eukaryotic DNA is packaged into nucleosomes, the smallest repeating unit of chromatin. The positions of nucleosomes determine the relative accessibility of genomic DNA. Several protocols exist for mapping nucleosome positions in eukaryotic genomes in order to study the relationship between chromatin structure and DNA-dependent processes. These nucleosome mapping protocols can be laborious and, at minimum, require two to three days to isolate nucleosome-protected DNA fragments. We have developed a streamlined protocol for mapping nucleosomes from $S$. cerevisiae liquid culture or from patches on solid agar. This method isolates nucleosome-sized footprints in three hours using $1.5 \mathrm{ml}$ tubes with minimal chemical waste. We validate that these footprints match those produced by previously published methods and we demonstrate that our protocol works for $N$. crassa and $S$. pombe. A slightly modified protocol can be used for isolation of nucleosome-protected DNA fragments from a variety of wild fungal specimens thereby providing a simple, easily multiplexed and unified strategy to map nucleosome positions in model and non-model fungi. Finally, we demonstrate recovery of nucleosome footprints from the diploid myeloid leukemia cell line PLB-985 in less than three hours using an abbreviated version of the same protocol. With reduced volume and incubation times and a streamlined workflow, the described method should be compatible with high-throughput, automated creation of MNase-seq libraries. We believe this simple validated method for rapidly producing sequencing-ready nucleosome footprints from a variety of organisms will make nucleosome mapping studies widely accessible to researchers globally.
\end{abstract}

Keywords: Nucleosome Mapping, Nucleosome Positioning, Chromatin Digestion, Rapid MNase

\section{Introduction}

Eukaryotic genomes are packaged into chromatin, where octamers of histone proteins are wrapped by $\sim 146$ base pairs of DNA to form repeating units known as nucleosomes (KORNBERG 1974; KoRNBERG AND THOMAs 1974; Luger et al. 1997). These nucleosomes are distributed nonrandomly throughout the genome and regulate access of underlying DNA to processes that require DNA association, such as transcription, replication, DNA repair and transcription factor binding (MACAlPine AND AlmouZni 2013; VenKATESH AND WoRKMAN 2015; HAUER AND GASSER 2017). Because the positions of nucleosomes play an integral role in regulating DNA-dependent processes, techniques to determine the positions of nucleosomes on the genome are employed widely across organisms (LEE et al. 2007; MAVRICH et al. 2008; VALOUEV et al. 2008; VALOUEV et al. 2011).

One common strategy to map nucleosome footprints uses micrococcal nuclease (MNase), which preferentially digests DNA between nucleosomes to leave behind nucleosome-protected stretches of DNA. This has more recently been coupled to high-throughput sequencing to obtain genome-wide nucleosome positioning profiles for many eukaryotic organisms (HENIKOFF et al. 2011; CUI AND ZHAO 2012). Since there is wide interest in understanding how proper nucleosome positions are established and altered within an organism in various environmental conditions, nucleosome mapping protocols continue to be used to dissect fundamental mechanisms in chromatin biology.

Sequencing of nucleosome-protected DNA fragments has uncovered a detailed understanding of mechanisms leading to regular nucleosome positioning in yeast and other organisms (LANTERMANN et al. 2010;
GKIKOPOULOS et al. 2011; ZHANG et al. 2011; POINTNER et al. 2012; KRIETENSTEIN et al. 2016; WIECHENS et al. 2016; BALDI et al. 2018). More recently, sophisticated technology has been adopted to map nucleosomes with higher precision (BROGAARD et al. 2012; CHEREJ et al. 2018) or to quantitatively gauge true nucleosome occupancy (CHEREJI et al. 2019; OBERBECKMANN et al. 2019). Nevertheless, there is still a significant need for simple and robust measurement of nucleosome positions across genomes. For this reason, various protocols for mapping nucleosome positions have been established in a wide range of organisms. These protocols are notably different not only between organisms, but can deviate significantly even within a single organism with highly variable cell number input, sample and reagent volumes, DNA purification methods and time commitments (Table 1). These differences make it challenging to identify an appropriate nucleosome mapping protocol for any specific organism and make it difficult to create a new mapping strategy for organisms that lack established protocols.

Here we have created a unified and streamlined strategy that isolates nucleosome footprints in roughly 3 hours, providing a rapid and validated means to create high-throughput sequencing libraries in a single day. Importantly, the same protocol can be used across model organisms. We show that our protocol works in $S$. cerevisiae (both liquid culture and solid patches), $S$. pombe, $N$. crassa, and human cells. In addition, we tested the protocol on multiple wild mushrooms and efficiently recovered nucleosome footprints, suggesting this protocol can likely be adapted as a starting point to map nucleosome positions in model and non-model eukaryotes. 
bioRxiv preprint doi: https://doi.org/10.1101/870659; this version posted December 11,2019 . The copyright holder for this preprint (which was not certified by peer review) is the author/funder, who has granted bioRxiv a license to display the preprint in perpetuity. It is made available under aCC-BY-NC 4.0 International license.

McKnight et al., 10 December 2019 - preprint copy - BioRxiv

\section{Results}

\section{Streamlined Protocol for Rapid Recovery of Nucleosome Footprints from $S$. cerevisiae}

The isolation of nucleosome-protected DNA is typically achieved through a similar procedure across all established protocols. For yeast, cells are generally crosslinked with formaldehyde to maintain nucleosome positions throughout the subsequent steps, though it has been debated whether these crosslinks can efficiently trap nucleosome positions without introducing artifacts (HENIKOFF et al. 2011; COLE et al. 2012). The cell walls are broken and nuclei are permeabilized to allow micrococcal nuclease to access and digest extranucleosomal DNA.

Cellular RNA is removed, formaldehyde crosslinks are reversed and protein is digested prior to DNA purification. Finally, the residual $3^{\circ}$ phosphates (from MNase cleavage activity) are removed prior to genomic library construction. Our protocol preserves all of these standard steps, but optimizes the workflow to achieve this process using small volumes while eliminating an entire day of experiment time (Figure 1A,
Table 1). The largest time savings compared to other fungi-specific MNase protocols are 1) reduction of time for proteinase $\mathrm{K}$ treatment and formaldehyde crosslink reversal from overnight to 45 minutes and 2) elimination of phenol/chloroform extraction and ethanol precipitation in favor of column-based DNA purification.

While the rapid MNase strategy can reproducibly recover well-digested nucleosome ladders, we wished to validate that the recovered nucleosome footprints did not deviate from expected genomic positions. To validate the rapid MNase approach, we created genome-wide MNase-seq libraries and mapped nucleosome positions in a wild type and isw2 yeast using the new protocol and a previously-published protocol (RODRIGUEZ et al. 2014). We chose Isw2-deficient yeast because Isw2 is required for nucleosome shifts at specific target loci, which allows us to determine if our protocol can recapitulate Isw2-specific nucleosome positions at target sites. For all samples, nucleosome organization at transcription start sites (TSSs) displayed the stereotypical structure, with a nucleosome-depleted region flanked by packed nucleosome arrays (Figure 1B). Comparison of nucleosome positions at
A

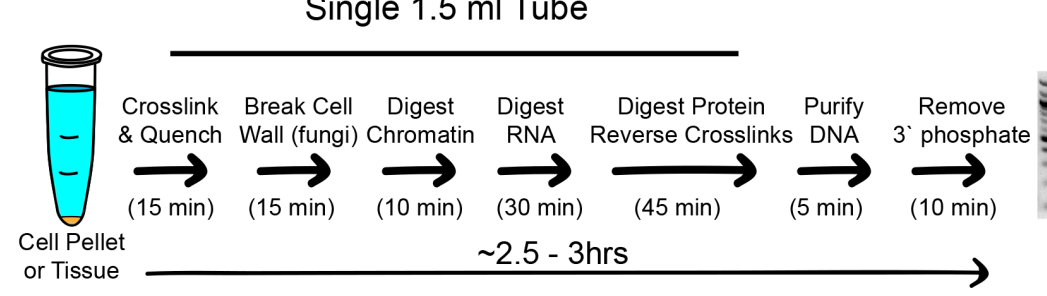

B
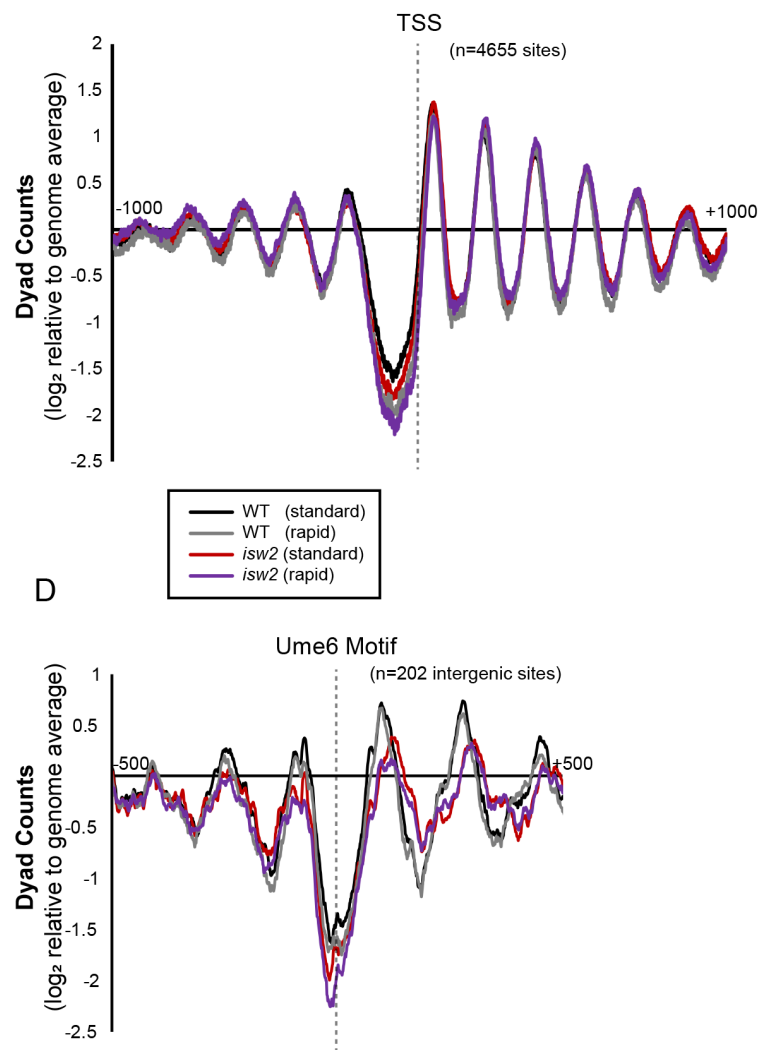

C

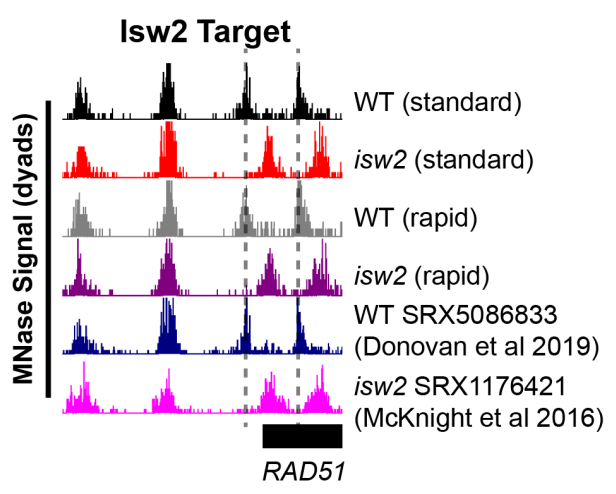

E Isw2/Ume6 Target

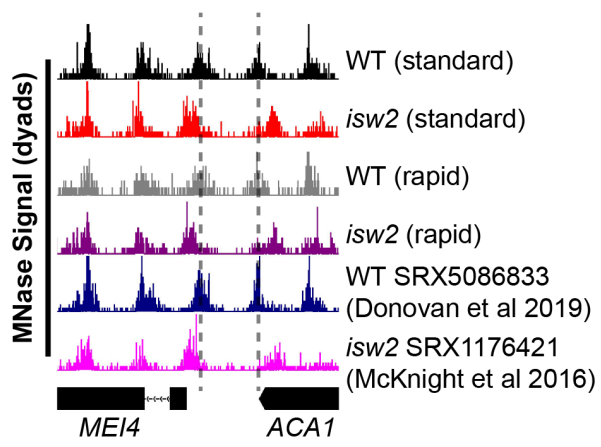

Figure 1. Rapid MNase can Accurately Map Nucleosome Positions in S. cerevisiae Cells. (A) Schematic of rapid MNase workflow beginning with a pellet ( 200 million cells) of uncrosslinked $S$. cerevisiae cells in a $1.5 \mathrm{ml}$ tube. Cells are crosslinked, spheroplasted, treated with MNase, RNase $A$, proteinase $K$ while reversing crosslinks, and DNA is purified by spin column prior to phosphatase treatment. A $2 \%$ agarose gel showing an example digestion of WT and isw2 yeast from exponentially-growing cells in YPD is shown (right). (B) Nucleosome dyad signal at 4655 yeast transcription start sites (TSSs) are plotted for WT and isw2 nucleosomes harvested using a standard (RODRIGUEZ et al. 2014) or rapid protocol. (C) Example Genome Browser image showing the standard method and rapid method can map Isw2-directed nucleosome positions similar to published data sets at the $R A D 51$ locus. Dashed lines indicate Isw2-positioned nucleosomes. (D) Nucleosome dyad signal at 202 intergenic Ume6 target sites showing rapid and standard MNase methods can accurately identify global changes in nucleosome structure at an Isw2 recruitment motif. (E) Genome Browser image showing all methods correctly identify Isw2-positioned nucleosomes at the MEI4-ACA1 locus, a Ume6 target site. Dashed lines indicate Ume6- and Isw2positioned nucleosomes. 
bioRxiv preprint doi: https://doi.org/10.1101/870659; this version posted December 11, 2019. The copyright holder for this preprint (which was not certified by peer review) is the author/funder, who has granted bioRxiv a license to display the preprint in perpetuity. It is made available under aCC-BY-NC 4.0 International license.

McKnight et al., 10 December 2019 - preprint copy - BioRxiv

A

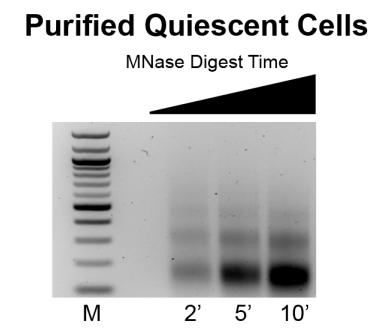

C
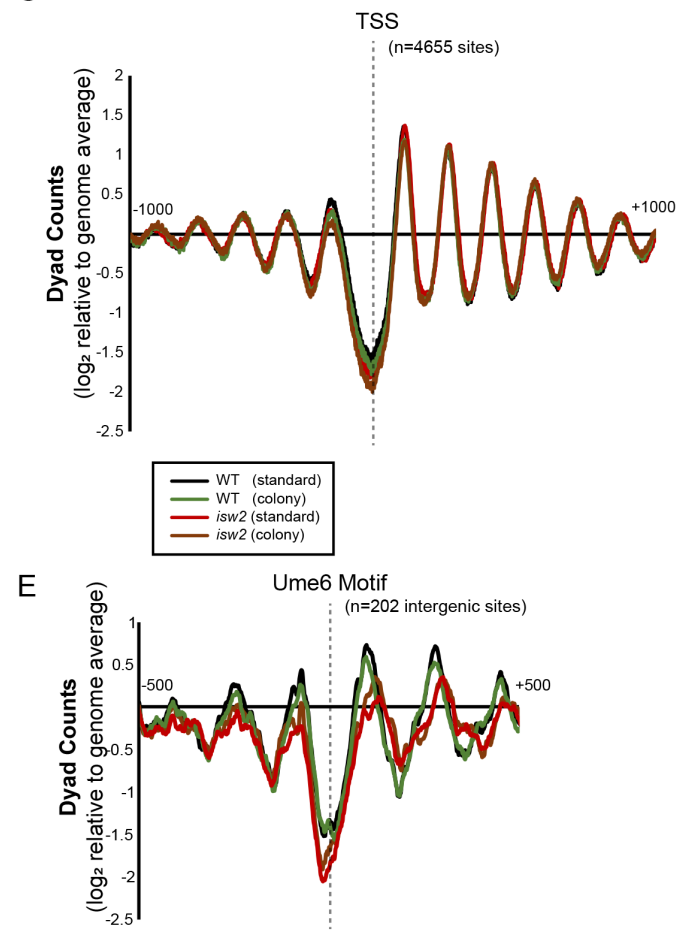

B

\section{"Colony" MNase}

Patch on YPD-Agar

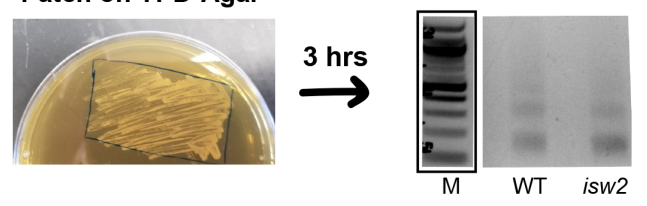

D

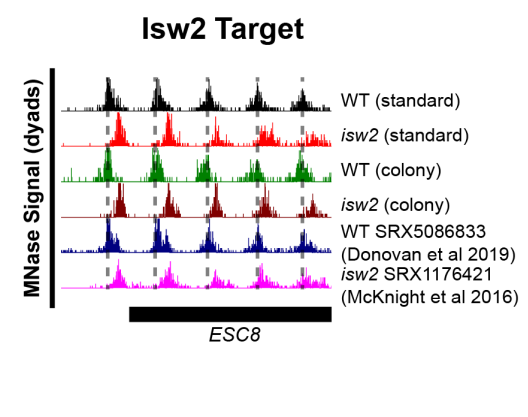

Isw2/Ume6 Target

$\mathrm{F}$

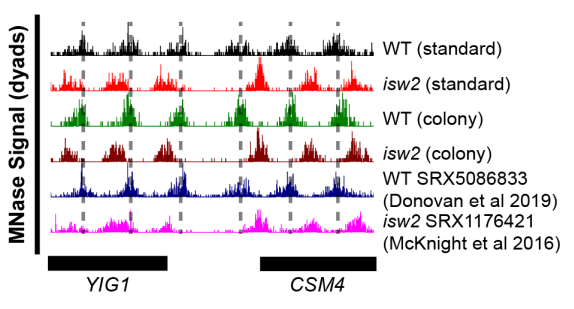

Figure 2. Rapid MNase can Recover Nucleosome Footprints from Isolated Quiescent Cells and Yeast Patches. (A) Representative gel showing nucleosome footprints recovered from purified quiescent cells using the rapid MNase protocol. (B) Representative gel (right) showing nucleosome footprints recovered from a fresh patch of yeast collected from YPD-Agar (left). (C) Nucleosome dyad signal at transcription start sites (TSSs) comparing standard (Rodriguez et al. 2014) and patchrecovered "colony" MNase footprints. (D) Example Genome Browser image showing "colony" MNase footprints can accurately identify Isw2-directed nucleosome positions at the ESC8 locus compared to the standard MNase protocol and published data sets. (E) Nucleosome dyad signal at 202 intergenic Ume6 target sites showing "colony" MNase can accurately identify global changes at an Isw2 recruitment motif. (F) Genome Browser image showing colony MNase can similarly identify Isw2-positioned nucleosomes at the YIG1-CSM4 locus, an example Ume6 target site. Dashed lines indicate Ume6- and Isw2-positioned nucleosomes.
Isw2 targets showed that nucleosomes were detected at strain-specific but not protocol-specific locations (Figure 1C). Both the rapid protocol and standard protocol recovered strain-specific nucleosome positioning at Ume6 binding sites, a known Isw2-recruitment protein (GOLDMARK et al. 2000), across the genome (Figure 1D,E). In sum, the rapid protocol can accurately map nucleosome positions and capture strain-specific nucleosome footprints.

We next asked whether the rapid MNase protocol could be applied to purified quiescent cells (ALLEN et al. 2006). To test this, we first purified quiescent yeast from 3-day saturated cultures using a Percoll gradient. As previously observed, quiescent yeast required longer treatment with an increased amount of Zymolyase (McKNIGHT et al. 2015) to compensate for a highly-fortified cell wall (Li et al. 2015). We observed that the rapid protocol with an extended Zymolyase incubation can efficiently and reproducibly recover nucleosome footprints (Figure 2A). Because of the protocol's simplicity, we suspected that we could similarly recover nucleosome footprints from patches of yeast grown on agar plates, or "colony MNase". Indeed, nucleosome footprints are readily recovered from solid-grown yeast (Figure 2B), and the captured nucleosome positions accurately reflect nucleosome positioning across the yeast genome (Figure 2C,D). Similar to liquid culture, the rapid colony MNase protocol can also detect Isw2-specific nucleosome positioning events genome-wide (Figure 2E,F).

\section{Rapid Recovery of Nucleosome Footprints from S. pombe and N. crassa}

After validating the rapid MNase protocol as a useful and versatile method to map nucleosomes in S. cerevisiae we wished to determine if the same protocol could be used for other fungal species. To test this, we first grew $S$. pombe in liquid culture and prepared MNase-seq libraries after using the rapid MNase protocol. Without any protocol modifications, we were able to recover a well-defined and appropriatelydigested nucleosome ladder from wild-type $S$. pombe cells (Figure 3A). We compared our sequencing data set with previously-published MNaseseq data sets from $S$. pombe cells (DEGENNARO et al. 2013; STEGLICH et al. 2015). Genomic nucleosome dyad positions from samples prepared by the rapid MNase protocol were the same as seen previously (Figure 3B). In addition, global nucleosome positioning at $S$. pombe TSSs was 
A

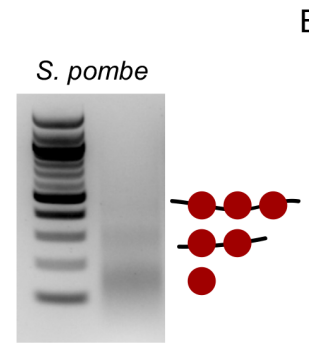

B

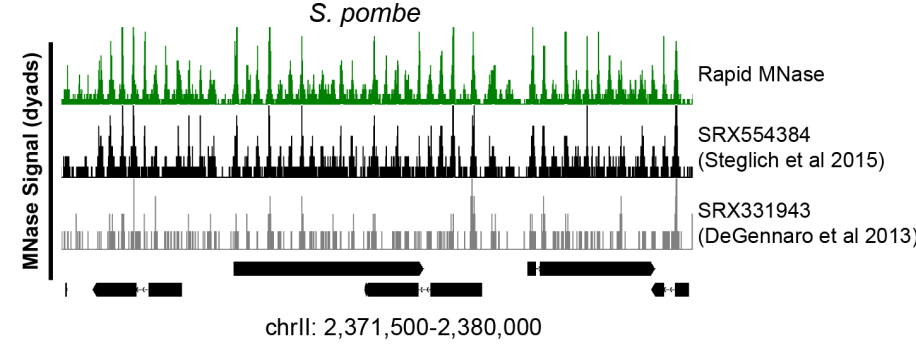

C

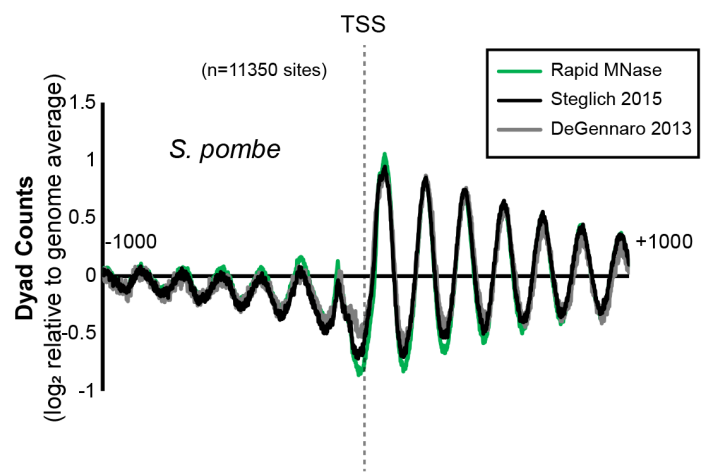

E

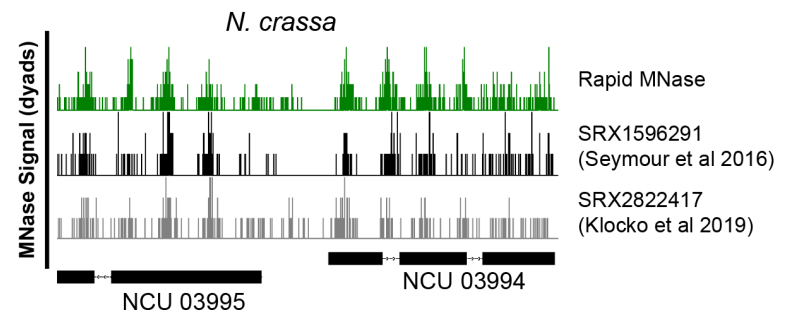

nearly identical across data sets indicating that rapid MNase can readily capture global nucleosome positions in S. pombe (Figure 3C). We next tried the rapid MNase protocol on crosslinked, germinated Neurospora crassa conidia. Similar to both S. cerevisiae and S. pombe cells, we were readily able to isolate nucleosome footprints from $N$. crassa using the rapid MNase protocol (Figure 3D). Importantly, we verified that the genomic nucleosome positions that we obtained were similar to previously-published N. crassa data sets (SEYMOUR et al. 2016; KLOCKO et al. 2019) (Figure 3E). Together these data validate the rapid MNase protocol as a reasonable, rapid strategy to map nucleosome positions in S. pombe and N. crassa, two widely-investigated model fungi.

\section{Recovery of Nucleosome Footprints from Wild Fungal Specimens}

After validating our protocol on multiple model fungi, we next asked if we could apply the rapid MNase protocol to non-model fungi. We foraged for local wild mushrooms and subjected them to the rapid MNase workflow. Interestingly, we successfully isolated mononucleosome-sized footprints from all wild mushrooms that we collected (Figure 4A). After optimizing the amount of input mushroom tissue to $50 \mathrm{mg}$, we could reproducibly obtain similarly-digested nucleosome ladders from multiple mushrooms, including commercially-important chanterelles, in under three hours (Figure 4B, top). Application of the optimized protocol to a newly-acquired specimen led to successful recovery of well-digested chromatin (Figure 4B, bottom) suggesting that nucleosomes can be digested and recovered from many wild mushrooms using this protocol.
Figure 3. Rapid MNase can Accurately Map Nucleosome Positions in $S$. pombe and $N$. crassa. (A) Agarose gel showing example nucleosome footprints recovered from $S$. pombe using the rapid MNase protocol. (B) Genome Browser image comparing nucleosome dyad positions on $S$. pombe chrll recovered for the rapid MNase protocol (top) and previouslypublished data sets. (C) Alignment of nucleosome dyads at 11,350 transcription start sites (TSSs) for rapid MNase-recovered nucleosome footprints and previously-published data sets. (D) Agarose gel showing example nucleosome footprints recovered from $N$. crassa using the rapid MNase protocol. (E) Genome Browser image comparing nucleosome dyad positions at the $N$. crassa NCU3995-NCU3994 locus for the rapid MNase protocol (top) and previously-published data sets.
This successful isolation of nucleosomes from previously-untested organisms suggests that the rapid MNase protocol can be applied across a wide variety of fungal species, and will be a useful and easy-toimplement approach to define MNase protocols in new systems.

\section{Recovery of Nucleosome Footprints from the PLB-985 Leukemia Cell Line}

Although the rapid MNase protocol was initially designed to expedite the recovery of nucleosomes from $S$. cerevisiae, our success in obtaining nucleosome footprints from multiple fungal species suggested that the protocol may be broadly applicable in other organisms. We tested whether we could use the rapid MNase protocol (without cell wall digestion) to isolate nucleosome footprints from PLB-985 cells, a diploid myeloid leukemia cell line. With a formaldehyde crosslinking step, reproducible nucleosome footprints were robustly recovered in less than 2.5 hours (Figure 5A). If crosslinking is omitted, since it is potentially less likely that nucleosome positions will change in the extremely short duration of the protocol, it is possible to recover library-ready nucleosome footprints in less than 1 hour (Figure 5B). Although previous MNase protocols in mammals could be performed in less than 1 day (Ramani et al 2019), the fact that our rapid protocol described herein can be used across organisms makes it a promising and standardized alternative to previously-published protocols across organisms. 
bioRxiv preprint doi: https://doi.org/10.1101/870659; this version posted December 11,2019 . The copyright holder for this preprint (which was not certified by peer review) is the author/funder, who has granted bioRxiv a license to display the preprint in perpetuity. It is made available under aCC-BY-NC 4.0 International license.

McKnight et al., 10 December 2019 - preprint copy - BioRxiv

A

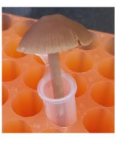

1

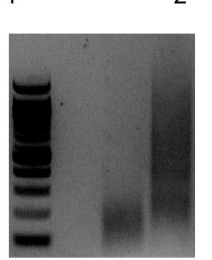

12

2
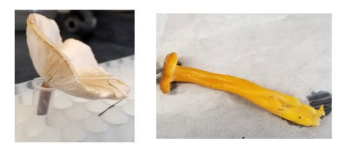

3

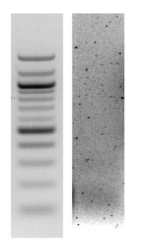

3

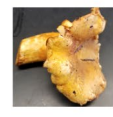

4

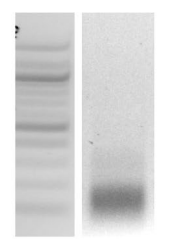

4
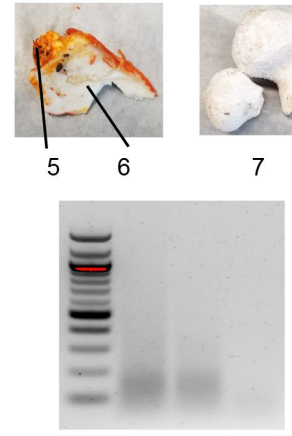

$\begin{array}{lll}5 & 6 & 7\end{array}$

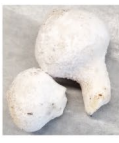

7
B
$50 \mathrm{mg}$

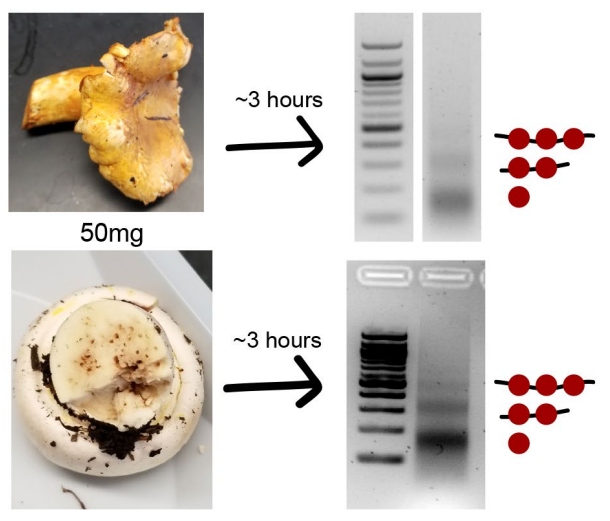

\section{Discussion}

In this work, we have optimized and validated a rapid protocol for mapping nucleosome positions in eukaryotic genomes. While our protocol is simple and robust across organisms, there are caveats that should be noted prior to implementing the defined protocol. First, MNase activity can vary across lots and vendors, so it is critical to calibrate the MNase concentration to give the desired extent of digestion. We have successfully optimized MNase concentration from multiple vendors and strongly recommend initial enzyme titrations. Second, within an organism, the number of cells used or amount of MNase added could vary depending on the growth conditions or media composition. It is therefore possible that specific conditions or mutant strains may require subtle changes to digestion amount, particularly if it is challenging to accurately quantify the initial number of cells. Finally, there are likely organisms that may require additional initial steps to help permeabilize cells, particularly if the cells possess Zymolyase -resistant cell walls. Previous work has demonstrated success using cryogrinding as the cell breaking step instead of Zymolyase (GonZALEZ AND SCAZZOCCHIO 1997; GIVENS et al. 2011). The presented protocol is a reliable starting point from which adjustments can rapidly and easily be made.

In conclusion, this rapid MNase protocol is capable of accurately mapping nucleosome positions in S. cerevisiae, S. pombe and N. crassa, providing identical nucleosome positions as previously-published protocols in only 3 hours. In addition to recapitulating nucleosome footprints from model species in significantly less time, the same protocol can be used to isolate nucleosome footprints rapidly from wild
A Recovered from Wild Mushroom Samples. (A) Images of locally-foraged wild mushrooms that were subjected to the rapid MNase protocol (top). Sample 5-6 consists of a distinct surface fungal specimen (5) growing on a host specimen (6). Recovered nucleosome footprints for corresponding mushrooms are shown (bottom). Speculative identities of these samples are (1) Panaeolus foenisecii, (2) unknown, (3) Craterellus tubaeformis, (4) Cantharellus formosus, (5) Hypomyces lactifluorum, (6) Russula brevines, (7) Lycoperdon perlatum. (B) Optimized rapid MNase for specimen 4 (chanterelle) was achieved using $50 \mathrm{mg}$ of tissue leading to well-digested nucleosome footprints (top). The optimized protocol was performed on $50 \mathrm{mg}$ of a previouslyuntested specimen leading to well-digested nucleosome footprints (bottom). Speculative identity of these samples are Cantharellus formosus (top) and Agricus xanthodermus (bottom).
Figure 4. Nucleosome Footprints can be Rapidly

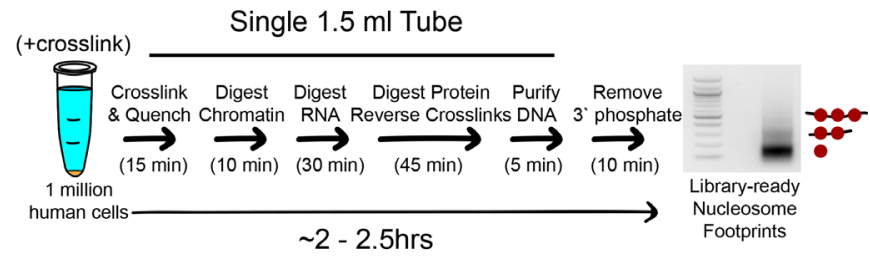

B

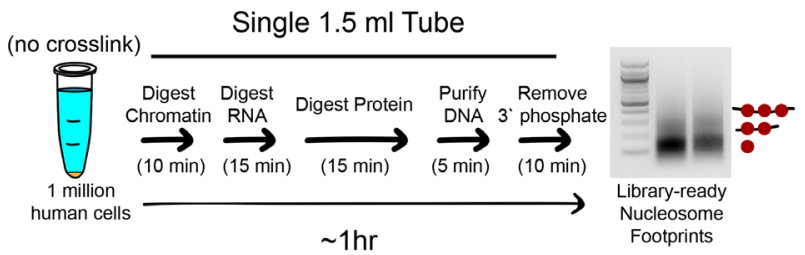

Figure 5. The Rapid MNase Protocol can be Performed on Human Cells with or without Crosslinking. (A) Cartoon schematic showing rapid MNase protocol and associated nucleosome footprints for 1 million human cells from the diploid myeloid leukemia cell line PLB-985. The protocol is identical to that in Figure 1A except there is no Zymolyase treatment. (B) Cartoon schematic showing rapid MNase protocol for PLB985 cells and associated nucleosome footprints when the crosslinking and crosslink reversal steps are omitted and other steps are shortened. The crosslink-free protocol can provide nucleosome footprints that are ready for library construction in less than 1 hour. 
bioRxiv preprint doi: https://doi.org/10.1101/870659; this version posted December 11, 2019. The copyright holder for this preprint (which was not certified by peer review) is the author/funder, who has granted bioRxiv a license to display the preprint in perpetuity. It is made available under aCC-BY-NC 4.0 International license.

McKnight et al., 10 December 2019 - preprint copy - BioRxiv

fungal species for which no previous MNase protocol has been established. Finally, our rapid MNase protocol can successfully recover library-ready nucleosomal DNA from human cells in $\sim 2.5$ hours if cells are first crosslinked or in $\sim 60$ minutes if cells are not crosslinked. The single, simple protocol that rapidly recovers nucleosome footprints across the multiple tested organisms provides a unified strategy to map nucleosome positions. Because all steps are carried out in a single $1.5 \mathrm{ml}$ tube using small volumes of reagents, it is likely that the described rapid MNase protocol can be easily adapted for automation. Based on our success in multiple systems, we believe that this simple protocol can be a first approach for mapping nucleosomes in organisms with or without established protocols.

\section{Materials and Methods}

\section{Growth Conditions}

For rapid MNase, an overnight culture grown in YPD was diluted to $\mathrm{OD}_{600}$ $=0.3$ in $25 \mathrm{ml}$ fresh YPD and grown at $30^{\circ} \mathrm{C}$ with shaking to a final $\mathrm{OD}_{600}=$ 0.8 (roughly $3^{*} 10^{8}$ cells). For "standard" protocol (RODRIGUEZ et al. 2014), an overnight culture was diluted to $O D_{600}=0.1$ in $250 \mathrm{ml}$ of culture and grown to $\mathrm{OD}_{600}=0.4-0.6$. The culture was crosslinked with $1 \%$ formaldehyde (final concentration), and incubated at $30^{\circ} \mathrm{C}$ with shaking for an additional 15 minutes. Crosslinking was quenched by the addition of glycine (final concentration $125 \mathrm{mM}$ ), and cells were pelleted at $3000 \mathrm{xg}$ for 5 minutes at $4^{\circ} \mathrm{C}$. The pellet was resuspended in $1 \mathrm{ml}$ of water, transferred to a $1.5 \mathrm{ml}$ microcentrifuge tube, and pelleted at maximum speed for $20 \mathrm{~s}$. Supernatant was removed completely with a pipette, and the pellet was flash frozen in liquid nitrogen and stored at $-80^{\circ} \mathrm{C}$.

For quiescent yeast, a $25 \mathrm{ml}$ culture was grown at $30^{\circ} \mathrm{C}$ with shaking for 3 days in YPD and quiescent cells were purified by Percoll gradient as previously described (ALLEN et al. 2006: MCKNIGHT et al. 2015). The dense fraction was collected, pelleted, and $\mathrm{OD}_{600}$ was determined after cells were resuspended in water. $A$ total of $100 \mathrm{OD}_{600}$ units of cells (approximately $3^{*} 10^{8}$ cells) was crosslinked with $1 \%$ formaldehyde (final concentration) for 15 minutes, quenched with $125 \mathrm{mM}$ glycine, pelleted and flash-frozen in a $1.5 \mathrm{ml}$ tube.

For yeast patches on YPD agar, a $\sim 1 \mathrm{~cm} \times 3 \mathrm{~cm}$ patch (Figure 2B) was made from a glycerol stock on YPD agar with appropriate selection and grown at $30^{\circ} \mathrm{C}$ overnight. The next morning the patch was collected with an inoculation loop and resuspended in $1 \mathrm{ml}$ YPD. The $\mathrm{OD}_{600}$ of a 1:20 dilution was measured and $30 \mathrm{OD}_{600}$ units of cells (roughly $10^{8}$ cells) was pelleted, resuspended in $1 \mathrm{ml}$ PBS and crosslinked with $1 \%$ formaldehyde for 15 minutes. Crosslinking was quenched with $125 \mathrm{mM}$ glycine, then cells were pelleted and used directly in the rapid MNase protocol.

For S. pombe, an overnight culture was grown in YES media and diluted to $\mathrm{OD}_{600}=0.3$ in $25 \mathrm{ml}$ fresh YES media. Cells were grown at $30^{\circ} \mathrm{C}$ with shaking until a final $\mathrm{OD}_{600}$ of 0.8 was reached. Cells were crosslinked with $1 \%$ formaldehyde for 15 minutes, quenched with $125 \mathrm{mM}$ glycine, pelleted and flash-frozen or used directly in the rapid MNase protocol.

For $N$. crassa, a $50 \mathrm{ml}$ culture in Vogel's medium with $1.5 \%$ sucrose was inoculated with $2.5^{\star} 10^{7}$ cells, harvested from freshly grown conidia, and grown at $32^{\circ} \mathrm{C}$ with shaking for $\sim 3.5$ hours, until at least $70 \%$ of conidia had germinated as determined microscopically. Cells were crosslinked by addition of fresh formaldehyde for a final concentration of $1 \%$, then shaken at room temperature for 10 minutes. The crosslinking reaction was quenched by the addition of $6.8 \mathrm{ml}$ of $1 \mathrm{M}$ Tris- $\mathrm{HCl} \mathrm{pH} 8$ to a final concentration of $125 \mathrm{mM}$ and shaken for 10 minutes at room temperature. Germinated conidia were then harvested by centrifugation. Supernatant was carefully removed with a pipette, leaving some media with the pellet. Conidia and remaining media were transferred a $1.5 \mathrm{ml}$ microcentrifuge tube and pelleted for 3 minutes. The pellet was resuspended in $1 \mathrm{ml}$ of $1 \mathrm{M}$ sorbitol, pelleted again at $8000 \mathrm{rpm}$ for 3 minutes and the final pellet was resuspended in $\sim 200$ ul of $1 \mathrm{M}$ sorbitol and stored at $-80^{\circ} \mathrm{C}$.

Wild mushrooms were picked on the University of Oregon campus and processed immediately or harvested in a nearby location and transported on dry ice prior to processing. Between 25 and $100 \mathrm{mg}$ of fruiting body was excised and crosslinked with $1 \%$ formaldehyde in $1 \mathrm{ml}$ phosphate-buffered saline for 15 minutes. Crosslinking was quenched with $125 \mathrm{mM}$ glycine, lightly disrupted with a wooden applicator stick, and tissue was pelleted at full speed in a microcentrifuge for 1 minute. The pellet was used directly in the rapid MNase protocol. Optimized samples (Figure 4B) used $50 \mathrm{mg}$ of mushroom tissue.
PLB-985 cells (TUCKER et al. 1987) were cultured to a density between $2 * 10^{5}$ and $2^{*} 10^{6}$ cells per $\mathrm{ml}$ in complete media [RPMI 1640 with HEPES and GlutaMAX (Gibco \#72400120), supplemented with $10 \%$ heatinactivated Fetal Bovine Serum (FBS), $100 \mathrm{IU}$ penicillin, $100 \mathrm{ug} / \mathrm{ml}$ streptomycin] at $37^{\circ} \mathrm{C}$ in a humidified atmosphere with $5 \% \mathrm{CO}_{2}$. One million cells were pelleted, resuspended in $1 \mathrm{ml}$ PBS, crosslinked with $1 \%$ formaldehyde for 15 minutes while rotating, quenched with $125 \mathrm{mM}$ glycine, pelleted, and used directly in the rapid MNase protocol. For samples that were not crosslinked, 1 million cells were washed once with PBS and pelleted cells were used directly in the rapid MNase protocol.

\section{Micrococcal Nuclease Digestion of Samples}

For rapid MNase, cells (S. cerevisiae pellets from liquid culture, $N$. crassa, $S$. pombe and wild mushrooms) were treated with $2 \mathrm{mg}$ of Zymolyase (100T, AMS Bio) in a $1 \mathrm{ml}$ solution of spheroplast buffer (1M sorbitol, $50 \mathrm{mM}$ Tris $\mathrm{pH} 7.5,10 \mathrm{mM}$ beta-Mercaptoethanol) for 15 minutes while rotating at room temperature. Quiescent yeast were treated with $10 \mathrm{mg}$ Zymolyase (100T, AMS Bio) for 1 hour. S. cerevisiae patches were treated with $2 \mathrm{mg}$ Zymolyase (100T, AMS bio) for 30 minutes. PLB-985 cells did not require Zymolyase treatment. Cells were pelleted at full speed and resuspended in 100 ul MNase digestion buffer ( $1 \mathrm{M}$ sorbitol, $50 \mathrm{mM} \mathrm{NaCl}, 10 \mathrm{mM}$ Tris $\mathrm{pH}$ $7.5,5 \mathrm{mM} \mathrm{MgCl}_{2}, 1 \mathrm{mM} \mathrm{CaCl} 2,0.075 \%$ (v/v) IGEPAL (Sigma), $0.5 \mathrm{mM}$ spermidine and $1 \mathrm{mM}$ beta-Mercaptoethanol; solution is stored at $-80^{\circ} \mathrm{C}$ before use). Exonuclease III (NEB) (30 units) and micrococcal nuclease (Worthington) (60 units for $S$. cerevisiae pellets from liquid cultures, $N$. crassa samples, S. pombe samples, wild mushrooms, PLB-985 cells; 30 units for S. cerevisiae patches; 4 units for quiescent yeast) were added to samples and rapidly mixed. Digestion proceeded for 10 minutes at $37^{\circ} \mathrm{C}$ (or for indicated times for quiescent cells) and was quenched with a final concentration of $5 \mathrm{mM}$ EGTA and $5 \mathrm{mM}$ EDTA (from $50 \mathrm{mM} / 50 \mathrm{mM}$ stock). RNase A $(50 \mathrm{mg}$ ) was added for 30 minutes (15 minutes for uncrosslinked PLB-985 cells) at $42^{\circ} \mathrm{C}$. Proteinase $\mathrm{K}(200 \mathrm{mg})$ was added for 45 minutes at $65^{\circ} \mathrm{C}$ (15 minutes for uncrosslinked PLB-985 cells). DNA footprints were recovered by MinElute PCR purification kit (Qiagen) and eluted with 12 ul of $1 \times$ Cutsmart buffer (NEB). For wild mushroom samples, after addition of buffer PB (Qiagen), samples were centrifuged for 2 minutes at full speed and the supernatant was applied to the MinElute column. Samples were treated with 5 units of Quick CIP (NEB) for 10 minutes at $37^{\circ} \mathrm{C}$. DNA was separated by $2 \%$ agarose gel electrophoresis and mononucleosome bands were gel-extracted (Qiagen MinElute) and converted to genomic libraries using the Ovation Ultralow Library System V2 (NuGEN) according to the manufacturer's instructions. Alternatively, Quick CIP was heatinactivated and DNA was directly converted to MNase-seq libraries using the Ovation Ultralow Library System or similar high-throughput DNA library protocol with similar results.

For the "standard" protocol (RODRIGUEZ et al. 2014), cells were resuspended in $40 \mathrm{ml}$ of spheroplast buffer (see above recipe) and treated with $5 \mathrm{mg}$ Zymolyase (100T, AMS Bio) for 15 minutes at room temperature and pelleted by centrifugation for 20 minutes at $4000 \times \mathrm{g}, 4^{\circ} \mathrm{C}$. Spheroplasts were resuspended in $2 \mathrm{ml}$ MNase digestion buffer (see above recipe) and divided into three 600 ul aliquots. Samples were digested with 10,20 or 40 units of MNase (Worthington) and 30 units of Exonuclease III (NEB) for 10 minutes. Digestion was quenched with 1\% SDS and 5mM EDTA (from 5\%/50mM stock) and treated with $200 \mathrm{mg}$ Proteinase $\mathrm{K}$ overnight at $65^{\circ} \mathrm{C}$. DNA was then purified by phenol/chloroform extraction and ethanol precipitation. Recovered DNA was resuspended in $60 \mathrm{ul} 1 \times$ NEB Buffer 2 and treated with $10 \mathrm{mg}$ RNase A for 1 hour at $37^{\circ} \mathrm{C}$. A 5 ul sample was analyzed by electrophoresis on $2 \%$ agarose gel and appropriately-digested samples were first purified by PCR purification kit (Qiagen), eluted with 50 ul of $1 \times$ NEB Buffer 3 and treated with 10 units of CIP (NEB) for 1 hour at $37^{\circ} \mathrm{C}$. Phosphatase-treated DNA was purified with a MinElute PCR purification kit and eluted in $12 \mathrm{u}$ buffer EB. The full sample was separated by electrophoresis on $2 \%$ agarose gel and the mononucleosome band was excised, gel extracted (Qiagen MinElute) and used for library creation using the Ovation Ultralow Library System V2 (NuGEN). Libraries were sequenced at the University of Oregon's Genomics and Cell Characterization Core Facility on an Illumina NextSeq 500 on the 37 cycle, paired-end, High Output setting, yielding approximately 20 million reads per sample.

\section{Data Processing}

MNase sequencing data were analyzed as described previously (MCKNIGHT AND TSUKIYAMA 2015). Briefly, paired-end reads were aligned to the S. cerevisiae sacCer3 (YATES et al. 2019), S. pombe (WOOD et al. 2002) or N. crassa (GALAGAN et al. 2003) reference genome with Bowtie 2 (LANGMEAD AND SALZBERG 2012), and filtered computationally for unique fragments between 100 and $200 \mathrm{bp}$. Dyad positions were calculated as the midpoint of paired reads, then dyad coverage was normalized across the genome for an average read/bp of 1.0. Nucleosome alignment to the Ume6 
bioRxiv preprint doi: https://doi.org/10.1101/870659; this version posted December 11,2019 . The copyright holder for this preprint (which was not certified by peer review) is the author/funder, who has granted bioRxiv a license to display the preprint in perpetuity. It is made available under aCC-BY-NC 4.0 International license.

McKnight et al., 10 December 2019 - preprint copy - BioRxiv

binding site, WNGGCGGCWW, was performed by taking average dyad signal at each position relative to all intergenic instances of a motif center. Intergenic instances of the Ume6 motif were found using the Saccharomyces Genome Database Pattern Matching tool (https://www.yeastgenome.org/nph-patmatch). Transcription start sites were obtained from published data sets for $S$. cerevisiae (NAGALAKSHMI et al. 2008) and S. pombe (THODBERG et al. 2019). Previously-published S. cerevisiae data (SRX5086833, (DONOVAN et al. 2019) ; SRX1176421, (MCKNIGHT et al. 2016)), S. pombe data (SRX554384, (STEGLICH et al. 2015) ; SRX331943, (DEGENNARO et al. 2013)) and N. crassa data (SRX1596291, (SEYMOUR et al. 2016) ; SRX2822417, (KLOCKO et al. 2019)) were downloaded from the Sequence Read Archive (SRA) and analyzed using our computational pipeline to identify nucleosome dyad positions. Data were visualized using Integrated Genome Browser (FREESE et al. 2016). Sequencing data from this work can be accessed at the GEO database under accession code GSE141676.

\section{Author Contributions}

Conceptualization, J.G.C. and J.N.M. ; Methodology, L.E.M., J.G.C., T.B.B., V.N.T., and J.N.M. ; Investigation, L.E.M., T.B.B., O.G.B.B., K.N.O., V.N.T., E.T.W., G.L.W., J.N.M. ; Resources, G.L.W., E.T.W., D.A.D., S.D.H., E.U.S. ; Writing - Original Draft, L.E.M., J.N.M. ; Writing - Reviewing and Editing, L.E.M., J.G.C., T.B.B., O.G.B.B., K.N.O., V.N.T. E.T.W., G.L.W., D.A.D., S.D.H., E.U.S., J.N.M. ; Visualization, J.N.M. ; Supervision, S.D.H., E.U.S., J.N.M. ; Project Administration, L.E.M., J.N.M. ; Funding Acquisition, J.N.M.

\section{Declaration of Interest}

The authors have no competing interests to declare.

\section{Data Availability}

The datasets generated during this study are available at GEO under accession code GSE141676.

\section{Acknowledgments}

The authors thank the Genomics Core $(\mathrm{GC} 3 \mathrm{~F})$ at the University of Oregon for high throughput sequencing services. The authors also thank Gabe Zentner (Indiana University), Christine Cucinotta (Fred Hutchinson Cancer Research Center) and Andrew Klocko (University of Colorado, Colorado Springs) for helpful discussions related to this work. The authors also acknowledge the Finkelstein Lab for the BioRxiv template. Mushroom identification was assisted by Andrew Kern (University of Oregon), Nicole Liachko (University of Washington), Richard Ebright (Rutgers University) and Anthoni Goodman (University of AlabamaBirmingham). This work was supported by a National Institutes of Health training grant T32 GM007759 (to O.G.B.B., K.N.O., G.L.W., and D.A.D.), by a National Institutes of Health training grant T32 GM007413 (to V.N.T.), by NIGMS GM093061 (to E.U.S.) and by NIGMS R01 GM129242 (to J.N.M.).

\section{References}

Allen, C., S. Buttner, A. D. Aragon, J. A. Thomas, O. Meirelles et al., 2006 Isolation of quiescent and nonquiescent cells from yeast stationaryphase cultures. J Cell Biol 174: 89-100.

Baldi, S., D. S. Jain, L. Harpprecht, A. Zabel, M. Scheibe et al., 2018 Genome-wide Rules of Nucleosome Phasing in Drosophila. Mol Cell 72: 661-672 e664.

Brogaard, K., L. Xi, J. P. Wang and J. Widom, 2012 A map of nucleosome positions in yeast at base-pair resolution. Nature 486: 496-501.

Cam, H. P., and S. Whitehall, 2016 Micrococcal Nuclease Digestion of Schizosaccharomyces pombe Chromatin. Cold Spring Harb Protoc 2016.
Chereji, R. V., T. D. Bryson and S. Henikoff, 2019 Quantitative MNase-seq accurately maps nucleosome occupancy levels. Genome Biol 20: 198.

Chereji, R. V., S. Ramachandran, T. D. Bryson and S. Henikoff, 2018 Precise genome-wide mapping of single nucleosomes and linkers in vivo. Genome Biol 19: 19

Cole, H. A., B. H. Howard and D. J. Clark, 2012 Genome-wide mapping of nucleosomes in yeast using paired-end sequencing. Methods Enzymol 513: 145-168.

Cui, K., and K. Zhao, 2012 Genome-wide approaches to determining nucleosome occupancy in metazoans using MNase-Seq. Methods Mol Biol 833: 413-419.

DeGennaro, C. M., B. H. Alver, S. Marguerat, E. Stepanova, C. P. Davis et al., 2013 Spt6 regulates intragenic and antisense transcription, nucleosome positioning, and histone modifications genome-wide in fission yeast. Mol Cell Biol 33: 4779-4792.

Donovan, D. A., J. G. Crandall, O. G. B. Banks, Z. D. Jensvold, V. Truong et al., 2019 Engineered Chromatin Remodeling Proteins for Precise Nucleosome Positioning. Cell Rep 29: 2520-2535 e2524.

Freese, N. H., D. C. Norris and A. E. Loraine, 2016 Integrated genome browser: visual analytics platform for genomics. Bioinformatics 32: 2089-2095.

Galagan, J. E., S. E. Calvo, K. A. Borkovich, E. U. Selker, N. D. Read et al., 2003 The genome sequence of the filamentous fungus Neurospora crassa. Nature 422: 859-868.

Givens, R. M., L. D. Mesner, J. L. Hamlin, M. J. Buck and J. A. Huberman, 2011 Integrity of chromatin and replicating DNA in nuclei released from fission yeast by semi-automated grinding in liquid nitrogen. BMC Res Notes 4: 499.

Gkikopoulos, T., P. Schofield, V. Singh, M. Pinskaya, J. Mellor et al., 2011 A role for Snf2-related nucleosome-spacing enzymes in genome-wide nucleosome organization. Science 333: 1758-1760.

Goldmark, J. P., T. G. Fazzio, P. W. Estep, G. M. Church and T. Tsukiyama, 2000 The Isw2 chromatin remodeling complex represses early meiotic genes upon recruitment by Ume6p. Cell 103: 423-433.

Gonzalez, R., and C. Scazzocchio, 1997 A rapid method for chromatin structure analysis in the filamentous fungus Aspergillus nidulans. Nucleic Acids Res 25: 3955-3956.

Hauer, M. H., and S. M. Gasser, 2017 Chromatin and nucleosome dynamics in DNA damage and repair. Genes Dev 31: 2204-2221.

Henikoff, J. G., J. A. Belsky, K. Krassovsky, D. M. MacAlpine and S. Henikoff, 2011 Epigenome characterization at single base-pair resolution. Proc Natl Acad Sci U S A 108: 18318-18323.

Klocko, A. D., M. Uesaka, T. Ormsby, M. R. Rountree, E. T. Wiles et al., 2019 Nucleosome Positioning by an Evolutionarily Conserved Chromatin Remodeler Prevents Aberrant DNA Methylation in Neurospora. Genetics 211: 563-578.

Kornberg, R. D., 1974 Chromatin structure: a repeating unit of histones and DNA. Science 184: 868-871.

Kornberg, R. D., and J. O. Thomas, 1974 Chromatin structure; oligomers of the histones. Science 184: 865-868.

Krietenstein, N., M. Wal, S. Watanabe, B. Park, C. L. Peterson et al., 2016 Genomic Nucleosome Organization Reconstituted with Pure Proteins. Cell 167: 709-721 e712.

Kubik, S., M. J. Bruzzone, P. Jacquet, J. L. Falcone, J. Rougemont et al., 2015 Nucleosome Stability Distinguishes Two Different Promoter Types at All Protein-Coding Genes in Yeast. Mol Cell 60: 422-434.

Langmead, B., and S. L. Salzberg, 2012 Fast gapped-read alignment with Bowtie 2. Nat Methods 9: 357-359.

Lantermann, A. B., T. Straub, A. Stralfors, G. C. Yuan, K. Ekwall et al., 2010 Schizosaccharomyces pombe genome-wide nucleosome mapping reveals positioning mechanisms distinct from those of Saccharomyces cerevisiae. Nat Struct Mol Biol 17: 251-257. 
bioRxiv preprint doi: https://doi.org/10.1101/870659; this version posted December 11,2019 . The copyright holder for this preprint (which was not certified by peer review) is the author/funder, who has granted bioRxiv a license to display the preprint in perpetuity. It is made available under aCC-BY-NC 4.0 International license.

McKnight et al., 10 December 2019 - preprint copy - BioRxiv

Lee, W., D. Tillo, N. Bray, R. H. Morse, R. W. Davis et al., 2007 A highresolution atlas of nucleosome occupancy in yeast. Nat Genet 39: 1235-1244.

Li, L., S. Miles and L. L. Breeden, 2015 A Genetic Screen for Saccharomyces cerevisiae Mutants That Fail to Enter Quiescence. G3 (Bethesda) 5: 1783-1795.

Luger, K., A. W. Mader, R. K. Richmond, D. F. Sargent and T. J. Richmond, 1997 Crystal structure of the nucleosome core particle at $2.8 \mathrm{~A}$ resolution. Nature 389: 251-260.

MacAlpine, D. M., and G. Almouzni, 2013 Chromatin and DNA replication. Cold Spring Harb Perspect Biol 5: a010207.

Mavrich, T. N., C. Jiang, I. P. loshikhes, X. Li, B. J. Venters et al., 2008 Nucleosome organization in the Drosophila genome. Nature 453: 358-362.

McKnight, J. N., J. W. Boerma, L. L. Breeden and T. Tsukiyama, 2015 Global Promoter Targeting of a Conserved Lysine Deacetylase for Transcriptional Shutoff during Quiescence Entry. Mol Cell 59: 732743.

McKnight, J. N., and T. Tsukiyama, 2015 The conserved HDAC Rpd3 drives transcriptional quiescence in $S$. cerevisiae. Genom Data 6: 245-248.

McKnight, J. N., T. Tsukiyama and G. D. Bowman, 2016 Sequencetargeted nucleosome sliding in vivo by a hybrid Chd1 chromatin remodeler. Genome Res 26: 693-704.

Nagalakshmi, U., Z. Wang, K. Waern, C. Shou, D. Raha et al., 2008 The transcriptional landscape of the yeast genome defined by RNA sequencing. Science 320: 1344-1349.

Oberbeckmann, E., M. Wolff, N. Krietenstein, M. Heron, J. L. Ellins et al., 2019 Absolute nucleosome occupancy map for the Saccharomyces cerevisiae genome. Genome Res 29: 1996-2009.

Pointner, J., J. Persson, P. Prasad, U. Norman-Axelsson, A. Stralfors et al., 2012 CHD1 remodelers regulate nucleosome spacing in vitro and align nucleosomal arrays over gene coding regions in $S$. pombe. EMBO J 31: 4388-4403.

Ramani, V., R. Qiu and J. Shendure, 2019 High Sensitivity Profiling of Chromatin Structure by MNase-SSP. Cell Rep 26: 2465-2476 e2464.

Rodriguez, J., J. N. McKnight and T. Tsukiyama, 2014 Genome-Wide Analysis of Nucleosome Positions, Occupancy, and Accessibility in Yeast: Nucleosome Mapping, High-Resolution Histone ChIP, and NCAM. Curr Protoc Mol Biol 108: 2128 21-16.
Schwartz, U., A. Nemeth, S. Diermeier, J. H. Exler, S. Hansch et al., 2019 Characterizing the nuclease accessibility of DNA in human cells to map higher order structures of chromatin. Nucleic Acids Res 47: 1239-1254.

Seymour, M., L. Ji, A. M. Santos, M. Kamei, T. Sasaki et al., 2016 Histone H1 Limits DNA Methylation in Neurospora crassa. G3 (Bethesda) 6: 1879-1889.

Steglich, B., A. Stralfors, O. Khorosjutina, J. Persson, A. Smialowska et al., 2015 The Fun30 chromatin remodeler Fft3 controls nuclear organization and chromatin structure of insulators and subtelomeres in fission yeast. PLoS Genet 11: e1005101.

Thodberg, M., A. Thieffry, J. Bornholdt, M. Boyd, C. Holmberg et al., 2019 Comprehensive profiling of the fission yeast transcription start site activity during stress and media response. Nucleic Acids Res 47: 1671-1691.

Tucker, K. A., M. B. Lilly, L. Heck, Jr. and T. A. Rado, 1987 Characterization of a new human diploid myeloid leukemia cell line (PLB-985) with granulocytic and monocytic differentiating capacity. Blood 70: 372-378.

Valouev, A., J. Ichikawa, T. Tonthat, J. Stuart, S. Ranade et al., 2008 A high-resolution, nucleosome position map of $\mathrm{C}$. elegans reveals a lack of universal sequence-dictated positioning. Genome Res 18: 1051-1063.

Valouev, A., S. M. Johnson, S. D. Boyd, C. L. Smith, A. Z. Fire et al., 2011 Determinants of nucleosome organization in primary human cells. Nature 474: 516-520.

Venkatesh, S., and J. L. Workman, 2015 Histone exchange, chromatin structure and the regulation of transcription. Nat Rev Mol Cell Biol 16: 178-189.

Wiechens, N., V. Singh, T. Gkikopoulos, P. Schofield, S. Rocha et al., 2016 The Chromatin Remodelling Enzymes SNF2H and SNF2L Position Nucleosomes adjacent to CTCF and Other Transcription Factors. PLoS Genet 12: e1005940.

Wood, V., R. Gwilliam, M. A. Rajandream, M. Lyne, R. Lyne et al., 2002 The genome sequence of Schizosaccharomyces pombe. Nature 415: 871-880.

Yates, A. D., P. Achuthan, W. Akanni, J. Allen, J. Allen et al., 2019 Ensembl 2020. Nucleic Acids Res.

Zhang, Z., C. J. Wippo, M. Wal, E. Ward, P. Korber et al., 2011 A packing mechanism for nucleosome organization reconstituted across a eukaryotic genome. Science 332: 977-980. 
Table 1. Comparison of different protocols for isolating nucleosome footprints.

\begin{tabular}{|c|c|c|c|c|}
\hline & $\begin{array}{l}\text { Starting } \\
\text { Material }\end{array}$ & $\begin{array}{c}\text { Formaldehyde } \\
\text { Volume }\end{array}$ & $\begin{array}{c}\text { DNA Purification } \\
\text { Method }\end{array}$ & $\begin{array}{c}\text { Time Required } \\
\text { to Isolate } \\
\text { Nucleosome } \\
\text { Footprints } \\
\end{array}$ \\
\hline \multicolumn{5}{|c|}{ S. cerevisiae (log growth) } \\
\hline Rodriguez et al 2014 & $\begin{array}{l}200 \mathrm{ml} \text { liquid } \\
\text { culture }\end{array}$ & $5.5 \mathrm{ml}$ & $\begin{array}{l}\text { Phenol/chloroform } \\
\text { extraction and } \\
\text { ethanol } \\
\text { precipitation }\end{array}$ & 2 days \\
\hline Kubik et al 2015 & $\begin{array}{l}50 \mathrm{ml} \text { liquid } \\
\text { culture }\end{array}$ & $1.4 \mathrm{ml}$ & $\begin{array}{l}\text { Phenol/chloroform } \\
\text { extraction and } \\
\text { ethanol } \\
\text { precipitation }\end{array}$ & 1-1.5 days \\
\hline Cole et al 2012 & $\begin{array}{l}250 \mathrm{ml} \text { liquid } \\
\text { culture }\end{array}$ & None & $\begin{array}{l}\text { Phenol/chloroform } \\
\text { extraction and } \\
\text { ethanol } \\
\text { precipitation }\end{array}$ & $\sim 1.5$ days \\
\hline Rapid Protocol & $\begin{array}{l}25 \mathrm{ml} \text { liquid } \\
\text { culture }\end{array}$ & $650 \mathrm{ul}$ & MinElute column & 3 hours \\
\hline \multicolumn{5}{|c|}{ S. cerevisiae (quiescent) } \\
\hline McKnight et al 2015 & $\begin{array}{l}\text { Purified } \\
\text { quiescent } \\
\text { cells from } 25 \\
\text { ml culture } \\
\end{array}$ & $650 \mathrm{ul}$ & $\begin{array}{l}\text { Phenol/chloroform } \\
\text { extraction and } \\
\text { ethanol } \\
\text { precipitation }\end{array}$ & 2 days \\
\hline Rapid Protocol & $\begin{array}{l}\text { Purified } \\
\text { quiescent } \\
\text { cells from } 25 \\
\text { ml culture } \\
\end{array}$ & $650 \mathrm{ul}$ & MinElute column & $\sim 4$ hours \\
\hline \multicolumn{5}{|c|}{ S. cerevisiae (agar plate) } \\
\hline Rapid Protocol ${ }^{b}$ & $\begin{array}{l}\text { Patch on } \\
\text { agar plate } \\
\text { ( 108 cells) }\end{array}$ & $27 \mathrm{ul}$ & MinElute column & 3 hours \\
\hline \multicolumn{5}{|l|}{ S. pombe } \\
\hline Cam and Whitehall & $\begin{array}{l}100 \mathrm{ml} \text { liquid } \\
\text { culture }\end{array}$ & $2.7 \mathrm{ml}$ & $\begin{array}{l}\text { Phenol/chloroform } \\
\text { extraction and } \\
\text { ethanol } \\
\text { precipitation }\end{array}$ & 2 days \\
\hline Rapid Protocol & $\begin{array}{l}25 \mathrm{ml} \text { liquid } \\
\text { culture }\end{array}$ & $650 \mathrm{ul}$ & MinElute column & 3 hours \\
\hline
\end{tabular}


Table 1 (cont)

\begin{tabular}{|c|c|c|c|c|}
\hline \multicolumn{5}{|l|}{ N. crassa } \\
\hline Klocko et al 2019 & $\begin{array}{l}\text { Nuclei } \\
\text { isolated from } \\
500 \mathrm{ml} \\
\text { conidia }\end{array}$ & None & MinElute column & 2 days \\
\hline Seymour et al 2016 & $\begin{array}{l}\text { Chromatin } \\
\text { fraction from } \\
50 \mathrm{ml} \text { conidia }\end{array}$ & $275 \mathrm{ul}$ & $\begin{array}{l}\text { Phenol/chloroform } \\
\text { extraction and } \\
\text { ethanol } \\
\text { precipitation }\end{array}$ & 3 days \\
\hline Rapid Protocol & $50 \mathrm{ml}$ conidia & $1.4 \mathrm{ml}$ & MinElute column & 3 hours \\
\hline \multicolumn{5}{|l|}{ Mammalian Cells } \\
\hline Schwartz et al 2019 & $\begin{array}{l}\text { HeLa cells } \\
(150 \mathrm{~mm} \\
\text { plate, } 70- \\
80 \% \\
\text { confluence) }\end{array}$ & None & $\begin{array}{l}\text { Ethanol } \\
\text { precipitation }\end{array}$ & $\sim 2$ days \\
\hline Ramani et al 2019 & $\begin{array}{l}\text { Mouse } \\
\text { embryonic } \\
\text { stem cells } \\
\left(2.5^{*} 10^{6}\right. \\
\text { cells }) \\
\end{array}$ & None & $\begin{array}{l}\text { Phenol/chloroform } \\
\text { extraction and } \\
\text { ethanol } \\
\text { precipitation }\end{array}$ & $<1$ day \\
\hline Rapid Protocol & $\begin{array}{l}10^{6} \text { human } \\
\text { diploid cells } \\
\text { (PLB-985) }\end{array}$ & $27 \mathrm{ul}$ & MinElute column & $\sim 2.5$ hours \\
\hline \multicolumn{5}{|c|}{ Wild Mushrooms (various species) } \\
\hline Rapid Protocol ${ }^{b}$ & $\begin{array}{l}50 \mathrm{mg} \text { of } \\
\text { fruiting body }\end{array}$ & $27 \mathrm{ul}$ & MinElute column & 3 hours \\
\hline
\end{tabular}

${ }^{a}$ Times were estimated based on interpretation of described protocols

${ }^{b}$ No other protocols were identified to isolate nucleosome footprints for these types of samples 